\title{
MODIFIKASI COVER MENJADI INFRARED WINDOW MOTOR 362-MD1 UNTUK INSPEKSI THERMOGRAPH
}

\author{
Hamdi ${ }^{1}$, Junjung Dwi Laksana Aji \\ Jurusan Teknik Mesin Politeknik Negeri Jakarta \\ Jl.Prof.Dr. G.A. Siwabessy, Kampus UI Depok 16425 \\ E-mail: ${ }^{1}$ hamdiandy@yahoo.com
}

\begin{abstract}
Thermograph is recognized as one of the best methods for identifying problems with low, medium and high voltage electrical equipment. Thermograph is used as a qualitative and quantitative tool. Qualitative visual shaped images on Thermograph and quantitative infrared cameras in the form of temperature range. In the inspection Thermograph should open the cover of the motor so the danger that arises in Arc Flash Explosion, the danger of rotating equipment and the danger of flying carbon powder. Arc Flash Explosion events generally occur in high equipment because of defective tools or human error. Arc Flash Explosion will not occur without a trigger, with changes in pressure and temperature can cause a short circuit. Arc Flash Explosion occurs when an undesired electrical current flows through the air due to the accumulation of carbon powder, thus heating the air and causing an explosion. When the inspector is not equipped with a personal protective equipment located near Arc Flash. As a result inspector injury and even death. So it is necessary to develop a device for Thermograph inspection security that can separate two environments with different pressures and temperatures. The danger of rotating equipment and the danger of carbon powder flying. IR Window is a security device for Thermograph inspection. Because with the pair IR Window can provide assurance from the Arc Flash Explosion, the danger of rotating equipment and carbon powder hazards that fly because it does not open the motor cover. Thus, Thermograph inspectors can safely complete inspection without process interruption, faster, reduce the number of workers and more completed inspection so as to reduce the risk of equipment failure through routine monitoring techniques and prediction techniques.
\end{abstract}

Keywords: Thermograph, IR Window (InfraRed Window), Arc Flash Explosion

\begin{abstract}
ABSTRAK
Thermograph sebagai salah satu metode terbaik untuk mengidentifikasi masalah pada peralatan listrik tegangan rendah, menengah dan tinggi. Thermograph digunakan sebagai alat inspeksi kualitatif secara visual berbentuk gambar pada kamera infrared Thermograph dan kuantitatif berbentuk range suhu. Dalam inspeksi Thermograph harus membuka cover motor sehingga bahaya yang ditimbulkan yaitu Arc Flash Explosion, bahaya benda yang berputar dan bahaya serbuk karbon yang berterbangan. Peristiwa Arc Flash Explosion pada umumnya terjadi pada peralatan tegangan tinggi karena alat rusak ataupun kesalahan manusia. Arc Flash Explosion tidak akan terjadi tanpa adanya pemicu, dengan perubahan tekanan dan suhu dapat menyebabkan hubung singkat. Arc Flash Explosion terjadi ketika arus listrik yang tidak diinginkan mengalir melalui udara karena adanya akumulasi serbuk karbon, sehingga memanaskan udara dan menyebabkan ledakan. Ketika inspektor tidak dilengkapi dengan alat pelindung diri berada di dekat Arc Flash. Akibatnya inspektor mengalami cedera bahkan kematian. Sehingga perlu mengembangkan perangkat untuk keamanan inspeksi Thermograph yang dapat memisahkan dua lingkungan dengan tekanan dan suhu yang berbeda. Bahaya benda yang berputar dan bahaya serat karbon yang berterbangan. IR Window adalah perangkat keamanan untuk inspeksi Thermograph. Karena dengan di pasangnya IR Window dapat memberikan jaminan dari Arc Flash Explosion, bahaya benda berputar dan bahaya serbuk karbon yang berterbangan karena tidak membuka cover motor. Dengan demikian, inspektor Thermograph dapat menyelesaikan inspeksi dengan aman tanpa gangguan proses, lebih cepat, mengurangi jumlah pekerja dan lebih banyak inspeksi selesai sehingga dapat mengurangi risiko kegagalan peralatan melalui teknik pemantauan rutin dan teknik prediksi.
\end{abstract}

Kata kunci: Thermograph, IR Window (InfraRed Window), Arc Flash Explosio 


\section{PENDAHULUAN}

Thermograph adalah metode memeriksa peralatan listrik dan mekanik dengan mendapatkan gambar distribusi panas. Metode pemeriksaan ini didasarkan pada fakta bahwa sebagian besar komponen dalam suatu sistem menunjukkan peningkatan suhu. Pengukuran dengan metode thermograph ini memberitahu kita bahwa peralatan yang kita ukur masih dalam temperatur normalnya atau sudah memasuki fase abnormal. Ketika terjadi temperatur abnormal di suatu peralatan tampilan visual pada kamera thermograph akan menunjukan satu atau beberapa titik yang lebih terang dari titik lainya, dalam hal ini disebut titik panas atau hot spot. Hot spot tersebut mengindikasikan ter jadinya masalah pada peralatan. Salah satu contohnya yaitu sistem koneksi kabel yang kurang kencang. Hal ini sangat berbahaya bagi keberlangsungan peralatan tersebut. Maka dari itu, pada suatu industri untuk mengadakan inspeksi pencegahan ini salah satunya dengan metode thermograph.

PT. Holcim Indonesia Pabrik Cilacap adalah salah satu industri yang sangat memperhatikan unsur preventif maintenace dalam pemeliharaan peralatan di dalamnya. Sebagai contoh pada area Raw Mill dimana terdapat peralatan 362-MD1.

Dimana 362-MD1 peranya itu sangat penting karena sebagai sumber penggerak pada Raw Mill. Raw Mill merupakan salah satu proses utama pada pembuatan semen. Sehingga diharapkan tidak terjadi masalah pada 362-MD1. Inspeksi thermograph merupakan salah satu metode untuk mendeteksi peralatan sebelum terjadinya kerusakan. Pada inspeksi thermograph ada dua tempat yang harus diinspeksi. Pertama inspeksi thermograph pada carbon brush pada motor besar. Kedua inspeksi thermograph pada panel motor besar di Local Sub Station. Diperlukan inspektur untuk membuka cover atau panel motor besar, melakukan inspeksi thermograph dengan cover terbuka dapat membahayakan inspektor karena dapat menghirup serbuk karbon yang berterbangan, terkena benda berputar, dan terjadinya Arc Flash Explosion. Pekerjaan yang berbahaya tapi masih merupakan pekerjaan yang sangat penting untuk dilakukan. Kami mengusulkan solusi untuk memasang $I R$ Window yang memungkinkan inspektur melakukan inspeksi tanpa membuka panel.

Karena dengan di pasangnya $I R$ Window dapat memberikan jaminan aman dari Arc Flash Explosion. Dengan demikian, inspektor Thermograph dapat menyelesaikan inspeksi dengan aman tanpa gangguan proses dan lebih banyak inspeksi selesai sehingga dapat mengurangi risiko kegagalan peralatan melalui teknik pemantauan rutin dan teknik prediksi.

\section{METODE PENELITIAN}

Metode penelitian berguna untuk mencapai tujuan yang telah ditentukan dan menjawab permasalahan yang telah dirumuskan dengan berbagai macam tahap penelitian agar lebih terarah. Metode-metode yang digunakan untuk meyelesaikan penelitian ini meliputi: Melakukan Inspeksi Thermograph. Pada saat melakukan inspeksi thermograph dilakukanlah pengamatan langsung ke lapangan untuk mengetahui masalah yang terjadi pada proses inspeksi thermograph pada Motor Raw Mill 362-MD1. Fokus pengamatan ini yaitu pada komponen, keamanan inspektor saat proses inspeksi thermograph, dan titik lokasi masalah yang akan diangkat. 


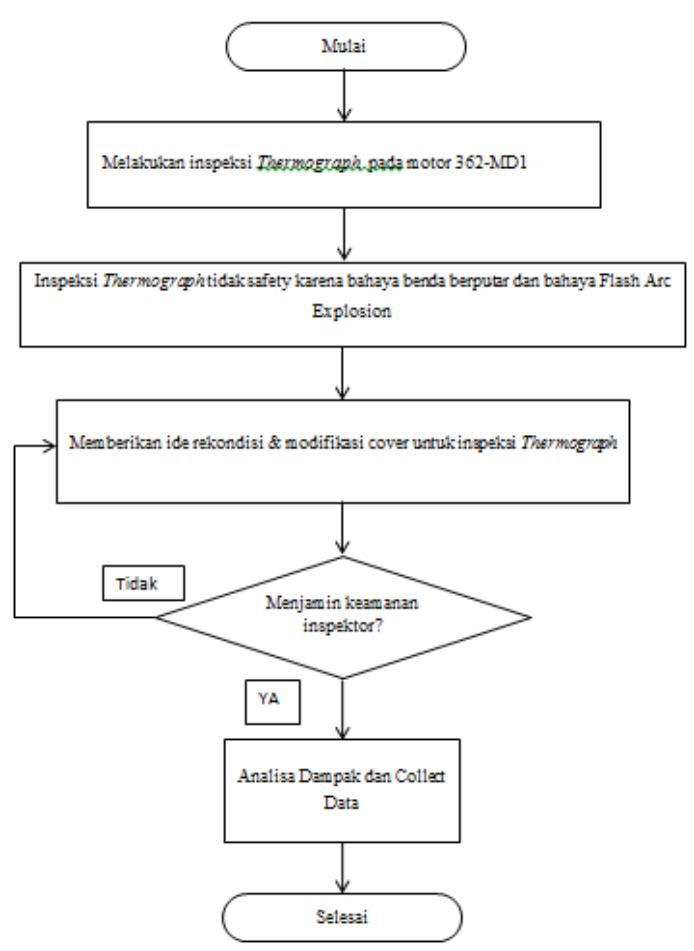

Gambar 1. Diagram alir penelitian

Inspeksi Thermograph Tidak Safety Mencari Root Cause Analysis (RCA) pada bahaya yang di timbulkan yaitu arc flash explosion dan bahaya benda berputar.

Setelah mendapatkan informasi mengenai akar masalah yang terjadi pada proses inspeksi Motor Raw Mill 362-MD1, pada tahap ini dilakukanlah diskusi dan penyelesaian masalah dengan Preventive Superintendant. Pihak-pihak lain yang juga terlibat dalam tahap ini ialah Electrical Raw Mill dan Inspektor Thermograph. Hasil diskusi untuk menjawab RCA yaitu dengan memasang IR Window.

Menjamin Keamanan Inspektor

Dengan di pasangnya IR Window akan menjamin inspektor dari bahaya benda berputar dan arc flash explosion karena tidak perlu membuka kover motor sehingga inspeksi di lakukan dari luar.

Analisa Dampak dan Collect Data

Di tahap ini, ada dua tahap yang dilakukan. Yang pertama ialah analisa dampak setelah dipasangnya IR Window yaitu inspektor lebih aman, inspeksi lebih cepat, dan menghemat tenaga. Yang kedua Collect Data dengan waktu inspeksi yang lebih cepat sehingga equipment lebih sering di inspeksi.

\section{HASIL dan PEMBAHASAN}

\section{National Fire Protection Association} (NFPA)

NFPA berfungsi untuk memastikan bahwa prosedur keselamatan diterapkan secara konsisten, NFPA 70E mengharuskan perusahaan untuk membuat program keselamatan listrik tertulis. Program ini harus mencakup persyaratan pelatihan untuk jenis pekerjaan yang akan dilakukan di fasilitas; penilaian bahaya listrik di fasilitas, seperti arc flash explosion; dan prosedur khusus untuk pemeliharaan yang diperlukan pada peralatan fasilitas. Informasi terkini dan akurat tentang sistem kelistrikan fasilitas juga diperlukan, seperti diagram satu garis dan spesifikasi peralatan.

Tujuan dari program semacam ini adalah untuk melindungi para pekerja dari bahaya arc flash explosion. Sistem yang efektif harus membangun budaya kesadaran keselamatan yang mencakup semua karyawan. Salah satu bagian kunci dari kesadaran keselamatan adalah memberikan informasi tentang bahaya apa pun yang ada, sehingga NFPA 70E mencakup persyaratan terperinci untuk pelabelan bahaya dan peralatan.

Arc Flash Explosion adalah pelepasan energi listrik secara tiba-tiba melalui udara ketika gap tegangan tinggi dan ada perbedaan antara konduktor. Arc Flash bisa spontan atau hasil dari tidak sengaja menjembatani kontak listrik dengan objek konduktor lain. Penyebabnya mungkin termasuk menjatuhkan alat atau penumpukan konduktif debu atau korosi. Flash busur mengeluarkan panas radiasi (panas) dan terang, cahaya kuat itu dapat menyebabkan luka bakar. Suhu Arc Flash Explosion mencapai $35.000{ }^{\circ} \mathrm{F}$. 
Busur tegangan tinggi juga dapat menghasilkan banyak gelombang tekanan dengan cepat memanaskan udara dan menciptakan ledakan. Ledakan ini dapat membuat tembaga dan aluminium mencair.

Berurusan dengan Arc Flash Explosion suatu pekerjaan mengharuskan pekerja untuk berinteraksi dengan peralatan yang masih bertegangan. Di mana inspeksi langsung harus dilakukan, salah satu perhatian utama adalah risiko dari Arc Flash Explosion. Bahaya ini sangat berbahaya karena kilatan busur terjadi paling sering selama pemeliharaan peralatan, ketika seorang pekerja berinteraksi langsung dengan peralatan. Busur kecil dapat muncul kapan pun, dan ketika sakelar pemutus dibuka atau ditutup. Jika busur ini terjadi bisa merusak dalam sekejap mata menjadi busur kilat.

Arc Flash Explosion tidak terjadi tanpa pemicu, ledakan terjadi karena "perubahan keadaan" yang menyebabkan hubungan sesaat antara fase 99\%. Arc Flash insiden disebabkan oleh intervensi - seseorang menghubungi komponen, dll Spontan busur berkedip sangat jarang terjadi. Sirkuit listrik harus diberi energi dan dimuat untuk inspeksi thermograph yang efektif. Semakin tinggi tegangan berarti bahaya yang terjadi lebih besar. Beberapa organisasi melarang inspeksi peralatan tegangan tinggi yang berenergi. IR Window adalah alternatif untuk membatasi anatara keadaan di dalam motor besar dengan keadaan di luar motor besar.

\section{IR Window (InfraRed Window)}

IR Window digunakan untuk memisahkan dua lingkungan dengan tekanan, suhu, kelembapan yang berbeda. Oleh karena itu, jendela IR harus memiliki karakteristik yang diperlukan untuk peralatan IR yang digunakan dan memenuhi persyaratan kekuatan, kekakuan dan lingkungan untuk jenis peralatan yang dipasangnya.
Idealnya, semua lingkup listrik arus tinggi dan menengah harus memiliki IR Window. Membuka kover motor untuk inspeksi inframerah membutuhkan waktu, tenaga kerja dan memiliki risiko keamanan; namun, umumnya fasilitas tidak mengalokasikan dana untuk menginstal windows di semua lingkup. Untuk memutuskan perangkat mana yang akan dipasang IR Window, pemasangan ini harus didasarkan pada beberapa faktor, termasuk yang berikut:

- Frekuensi inspeksi pada suatu peralatan tertentu

- Kompleksitas membuka panel

- Tindakan pencegahan arc flash explosion

- Persyaratan keamanan NFPA

Penggunaan IR Window cocok digunakan pada pusat pengendalian motor, panel distribusi, koneksi motor tegangan tinggi dan menengah serta koneksi kontrol

Awalnya, semua IR Windows terdiri dari lensa kristal. Sekarang terdapat IR Window dengan material Germanium, Zinc Selenide, dan Calcium Fluoride adalah bahan umum yang digunakan untuk membuat lensa.

\section{Keuntungan Kristal :}

- Ideal untuk suhu tinggi

- Tahan lingkungan yang ekstrim

- Memungkinkan inspeksi visual

- Kompatibel dengan semua IR Imagers

\section{Kekurangan Kristal :}

- Terbatas hingga diameter 4 "

- Bentuk bulat saja

- Tidak tahan benturan

- Biasanya lebih mahal daripada polimer

\section{Keuntungan Polimer:}

- Ideal untuk lingkungan industri

- Transmisivitas stabil dan konsisten

- Kompatibel dengan semua IR Imagers

- Pilihan ukuran dan bentuk tersedia

- Lebih murah dari kristal 


\section{Kekurangan polimer}

- Tidak cocok untuk lingkungan bersuhu tinggi (di atas $200^{\circ} \mathrm{C}$ )

- Seorang pakar harus dikonsultasikan sebelum memesan ukuran atau bentuk khusus (custom).

\section{KESIMPULAN}

IR Window untuk memenuhi persyaratan NFPA 70E saat melakukan inspeksi thermograph karena penggunaan IR Window dalam program inspeksi thermograph menghilangkan 99\% pemicu insiden Arc Flash Explosion.

IR Window menghapus risiko bahaya yang terkait dengan inspeksi thermograph. Memungkinkan satu termografer untuk menyelesaikan survei, sehingga mengurangi biaya tenaga kerja yang tinggi yang terkait dengan inspeksi thermograph.

Risiko bahaya yang terkait dengan inspeksi thermograph dapat di hapus karena IR Window dapat melindungi inspektur dari keausan karbon yang terhirup dan menghirupkan keausan karbon dapat menyebabkan beberapa masalah kesehatan sakit dada, menurunkan fungsi paru, pneumokoniosis grafit, melindungi inspektur dari berputar peralatan bahaya selama pemeriksaan thermograph dan melindungi dari arc flash explosion.

IR Window dapat mengurangi biaya tenaga kerja, durasi inspeksi thermografik dan tenaga kerja yang dibutuhkan

- Tanpa IR Window

$$
=2 \text { jam untuk } 2 \text { tenaga kerja }
$$

- Dengan IR Window

$$
=1 \text { jam untuk } 1 \text { tenaga kerja }
$$

- Biaya tenaga kerja per jam

$$
=\operatorname{Rp} 150.000
$$

- Frekuensi pemeriksaan untuk 362MD1 = 2 x per bulan
- Potensi penghematan biaya per bulan $=\operatorname{Rp} 900.000$

- Frekuensi inspeksi lebih banyak yang tadinya 2 minggu sekali menjadi seminggu sekali

IR Window yang digunakan pada koneksi motor tegangan tinggi dan menengah yaitu berbahan polimer karena berbahan polimer lebih cocok digunakan pada insudtri semen untuk ukuran yang optimal dari IR Window :

\section{DAFTAR PUSTAKA}

[1] A basic guide to Thermography

[2] "NFPA 70E Arc Flash". Graphic Products.

[3] KM Kowalski-Trakofler, EA Barrett, CW Urban, GT Homce "Arc Flash Awareness: Information and Discussion Topics for Electrical Workers". DHHS (NIOSH) Publication No. 2007116D. Accessed January 10, 2013.

[4] A Thermographer's Guide to Infrared Windows

[5] International Crystal Laboratories Optics \& Spectroscopy Supplies \& Accessories 


\section{LAMPIRAN}

Tabel 1. Panduan pemilihan material transmisi IR

\begin{tabular}{|c|c|c|c|c|}
\hline \multicolumn{2}{|c|}{ Material } & \multirow{2}{*}{$\begin{array}{l}\text { Skala } \\
\text { Transmisi } \\
\begin{array}{l}0.25- \\
15 \mu \mathrm{m}\end{array}\end{array}$} & \multirow{2}{*}{\begin{tabular}{|l|} 
Indeks \\
Pembiasan \\
1.52
\end{tabular}} & \multirow{2}{*}{\begin{tabular}{|l} 
Karakteristik Material \\
Umumnya dianggap sebagai jendela sel yang \\
paling berguna. NaCl berbiaya rendah dan kasar. \\
Hidroskopis.
\end{tabular}} \\
\hline $\mathrm{NaCl}$ & Rock Salt & & & \\
\hline $\mathrm{KBr}$ & $\begin{array}{l}\text { Potassium } \\
\text { Bromide }\end{array}$ & $\begin{array}{l}0.25- \\
25 \mu \mathrm{m}\end{array}$ & 1.53 & $\begin{array}{l}\text { KBr adalah material yang sangat bagus, berbiaya } \\
\text { rendah dengan jangkauan transmisi yang } \\
\text { diperpanjang. Lebih lembut daripada NaCl; } \\
\text { berdiri thermal dan mechanical shock dengan } \\
\text { cukup baik. Hidroskopis. }\end{array}$ \\
\hline $\mathrm{AgCl}$ & $\begin{array}{l}\text { Silver } \\
\text { Chloride }\end{array}$ & $0.4-23 \mu \mathrm{m}$ & 2.0 & $\begin{array}{l}\text { Bahan lembut. Gelap di bawah radiasi UV, tidak } \\
\text { larut dalam air. Digunakan sebagai windows sel } \\
\text { murah. Korosif terhadap logam. }\end{array}$ \\
\hline $\mathrm{CaF}_{2}$ & $\begin{array}{l}\text { Calcium } \\
\text { Fluoride }\end{array}$ & $0.15-9 \mu \mathrm{m}$ & 1.40 & $\begin{array}{l}\text { Indeks rendah dan kelarutan sangat rendah. } \\
\text { Membuat sel yang tahan lama dan tepat untuk } \\
\text { wilayah di mana ia mentransmisikan. Tidak larut } \\
\text { dalam air; tahan sebagian besar asam dan } \\
\text { alkalida. Jangan gunakan dengan larutan garam } \\
\text { ammonium. }\end{array}$ \\
\hline $\mathrm{BaF}_{2}$ & $\begin{array}{l}\text { Barium } \\
\text { Fluoride }\end{array}$ & $\begin{array}{l}0.2- \\
11.5 \mu \mathrm{m}\end{array}$ & 1.46 & $\begin{array}{l}\text { Bahan ini sangat sensitif terhadap thermal shock. } \\
\text { Jangan gunakan dengan larutan garam } \\
\text { ammonium. Tidak larut dalam air; memiliki } \\
\text { ketahanan yang baik terhadap fluor dan fluorida. }\end{array}$ \\
\hline CsI & $\begin{array}{l}\text { Cesium } \\
\text { Iodide }\end{array}$ & $1.5-50 \mu \mathrm{m}$ & 1.74 & $\begin{array}{l}\text { Umumnya lebih mudah ditangani daripada } \\
\text { cesium bromide. Hidroskopis; tidak pecah; mudah } \\
\text { tergores. }\end{array}$ \\
\hline $\begin{array}{l}\text { KRS- } \\
5\end{array}$ & $\begin{array}{l}\text { Thallium } \\
\text { Bromide- } \\
\text { Iodide }\end{array}$ & $0.5-35 \mu \mathrm{m}$ & 2.37 & $\begin{array}{l}\text { Mudah tergores; akan mengalir dingin; tidak } \\
\text { pecah; larut dalam basa; tidak larut dalam asam; } \\
\text { sedikit larut dalam air. Ideal untuk melemahkan } \\
\text { pantulan sinar total. Jangan menggiling atau } \\
\text { memoles. }\end{array}$ \\
\hline ZnSe & \begin{tabular}{|l} 
Zinc \\
Selenide
\end{tabular} & $1-18 \mu m$ & 2.4 & $\begin{array}{l}\text { Bahan ZnSe dalam kegunaan umum sama dengan } \\
\text { KRS-5. Tidak larut dalam air dan sangat tahan } \\
\text { terhadap sebagian besar pelarut. Interferensi } \\
\text { interferensi yang kuat dapat terjadi pada sel jalur } \\
\text { yang pendek. Ini rapuh dan karenanya harus } \\
\text { ditangani dengan sangat hati-hati. }\end{array}$ \\
\hline $\mathrm{MgF}_{2}$ & $\begin{array}{l}\text { Magnesium } \\
\text { Fluoride }\end{array}$ & $\begin{array}{l}0.11- \\
7.5 \mu \mathrm{m}\end{array}$ & $1.37-1.38$ & $\begin{array}{l}\text { Sedikit lebih larut daripada CaF2. Birefringent. } \\
\text { Mengirimkan dari ultraviolet vakum ke } \\
\text { inframerah. Sensitif terhadap thermal shock. }\end{array}$ \\
\hline Ge & Germanium & $2-11.5 \mu m$ & 4.0 & $\begin{array}{l}\text { Bahan indeks tinggi ini harus terbukti sangat } \\
\text { berguna untuk studi permukaan dan mungkin } \\
\text { sebagai jendela proses. Secara kimia inert, keras } \\
\text { dan rapuh. Harus ditangani dengan sangat hati- } \\
\text { hati, cenderung patah. }\end{array}$ \\
\hline $\mathrm{KCl}$ & $\begin{array}{l}\text { Potassium } \\
\text { Chloride }\end{array}$ & $\begin{array}{l}0.18- \\
20 \mu \mathrm{m}\end{array}$ & 1.46 & $\begin{array}{l}\mathrm{KCl} \text { mirip dengan } \mathrm{NaCl} \text {, tetapi tidak populer. } \\
\text { Pilihan kami atas } \mathrm{NaCl} \text { untuk bahan sel dasar } \\
\text { karena kurang higroskopis, mentransmisikan }\end{array}$ \\
\hline
\end{tabular}


POLITEKNOLOGI VOL. 17 NO. 3, SEPTEMBER 2018

\begin{tabular}{|l|l||l|l|l||}
\hline \multicolumn{1}{|l||}{} & & & $\begin{array}{l}\text { lebih jauh ke dalam jangkauan inframerah, dan } \\
\text { tahan kejutan termal. }\end{array}$ \\
\hline \hline $\mathrm{ZnS}$ & $\begin{array}{l}\text { Irtran-2 } \\
\text { Zinc Sulfide }\end{array}$ & $1-14 \mu \mathrm{m}$ & 2.20 & $\begin{array}{l}\text { Tidak larut dalam air. Agak larut dalam asam, } \\
\text { HNO3, H2SO4, dan KOH. }\end{array}$ \\
\hline \hline $\mathrm{SiO}_{2}$ & $\begin{array}{l}\text { Infrasil } \\
\text { Quartz }\end{array}$ & $0.4-4 \mu \mathrm{m}$ & $\begin{array}{l}1.5 \mathrm{at} \\
3333 \mathrm{~cm}^{-1}\end{array}$ & Tidak larut dalam air. \\
\hline \hline
\end{tabular}

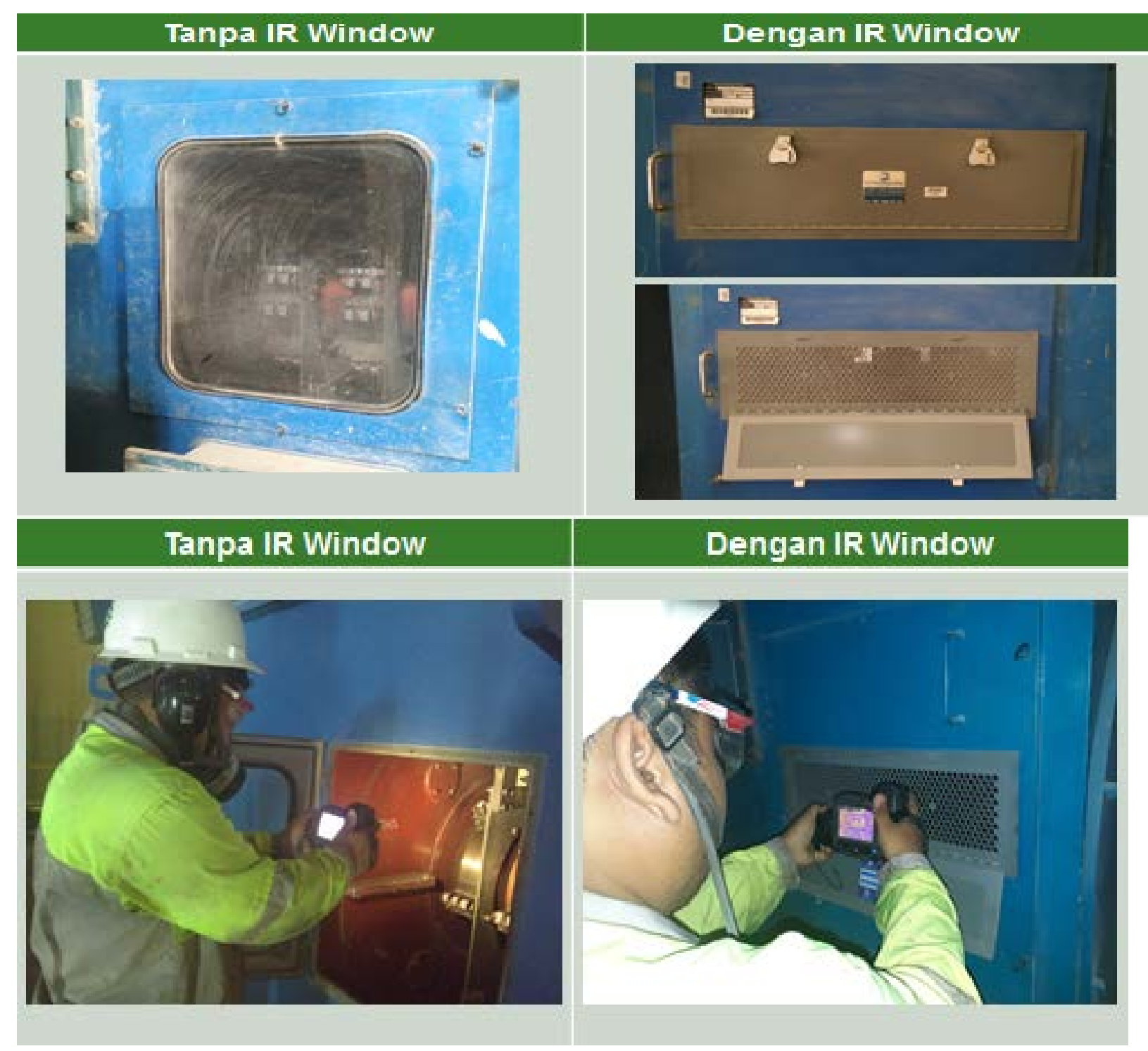

Gambar 2. Perbandingan dengan IR Window dan tanpa IR Window 
Hamdi dan Junjung Dwi Laksana Aji, Modifikasi Cover Menjadi.....

Tabel 2. Perbandingan dengan IR Window dan tanpa IR Window

\begin{tabular}{|l|l|}
\hline Tanpa IR Window & Dengan IR Window \\
\hline $\begin{array}{l}\text { Membutuhkan lebih banyak waktu } \\
\text { dan usaha }\end{array}$ & Pemeriksaan lebih cepat \\
\hline Membutuhkan lebih dari 1 orang & $\begin{array}{l}\text { Mampu dilakukan dengan hanya 1 } \\
\text { orang }\end{array}$ \\
\hline Kontaminan debu pada motor & Mengurangi kontaminan debu \\
\hline $\begin{array}{l}\text { Kemungkinan menghirup serbuk } \\
\text { karbon yang berterbangan }\end{array}$ & $\begin{array}{l}\text { Melindungi pekerja dari serbuk karbon } \\
\text { yang berterbangan }\end{array}$ \\
\hline Bahaya peralatan berputar Arc Flash & Perlindungan peralatan berputar \\
\hline $\begin{array}{l}\text { Tidak ada perlindungan } \\
\text { Explosion }\end{array}$ & Perlindungan dari Arc Flash Explosion \\
\hline
\end{tabular}

